\title{
NOVAS ALTERNATIVAS DE FINANCIAMENTO PARA A AGRICULTURA BRASILEIRA
}

\author{
Pedro Carlos Gama da Sitva' \\ Robéno Ferreira dos Santos"
}

\section{INTRODUÇÃO}

Muito tem se escrito sobre o crédito rusal no Brasil, tanto sobre o sistema oficial de distribuição social e espacial dos recursos dos financiamentos quanto sobre as politicas públicas adotadas. Os estudos existentes centram-se, no entanto, quase exclusivamente nas aplicações realizadas no mercado formal ou institucional. $O$ objetivo deste trabatho è situar em que contexto aparecen as novas altemativas de financiamento para a agrcultura brasileira, inclusive os sistemas informais de crédito cooperativo, a partir dos estudos existentes que tratam da evolução das instituiçôes, programas e politicas crediticias que afetam a agricultura.

Ele é dividido em outras cinco seções, além desta e das referências bibliográficas. Na $2^{\circ}$ seção é revisitada a relação entre crédito agricola e modernização da agricultura brasileira, nas seguintes são abordados o crédito agricola-cooperativo no Brasil, a relação entre crédito rural e desenvolvimento, o crédito rurai alternativo e algumas considerações a guisa de conclusões

\footnotetext{
Pesquisador da EMBRAPA-CPATSA. Petrolina, PE. Mestre em Economia. UFPB

"Pesquisador da EMBRAPA-CNPA, Professor do Curso de Mestrado em Economia, UFPB, Campus IJ Doutor em Economia pela USP.
}

Rev. Raizes, Compina Grande, Ano.XV" n" 11, pp.85-102. Jumo 1995. 


\section{CRÉDITO AGRICOLA E MODERNIZAÇĀO DA AGRICULTURA BRASILEIRA}

Vários são os estudos que abordam o crédito rural, principalmente a partir da sua institucionalização, com a criação do Sistema Nacional de Crédito Rural - SNCR, através da Lei n 4.829 , de 05 de novembro de 1965 (Pinto, 1981; Munhoz, 1982; Sayad, 1984; Delgado, 1985; Hoffmann \& Kageyama, 1987; Santos, 1988; Cardoso, 1988; Silva, 1990). Segundo Silva (1990), a partit dai, a implementação do crédito rural definiu explicitamente, com seus objetivos: o provimento de fundos externos para financiar uma parm cela considerável dos custos diretos de produção e comercialização da agricultura; o estímulo à formação de capital; a aceleração do processo de adoção tecnológica, e o fortalecimento da posição das economias dos produtores agrícolas, especialmente das categorias dos pequenos e médios. Uma análise da aplicação dos recursos em crédito rural até o início da década de 90 , permite inferir que os três primeiros objetivos-metas puderam ser atendidos até 1979, uma vez que até este ano o volume aplicado de crédito foi crescente em termos reais $^{1}$, viabilizando o novo modelo agrícola calcado na tecnificação $\mathrm{e}$ utilização maciça de insumos industriais e concorrendo para a consolidação do complexo agroindustrial brasileiro (Sorj, 1980; Silva, 1982; Martine \& Beskow, 1987).

Quanto à distribuição social e espacial dos recursos dos financiamentos, os estudos de Pinto (1981), Sayad (1984), Hoffmann \& Kageyma (1987) e Cardoso (1988), entre outros, revelam a natureza concentradora e excludente do crédito riral, demonstrando a pouca participação dos pequenos produtores. Sem dúvida, houve uma grande con-

\footnotetext{
${ }^{1}$ Os recursos destinados ao crédito rural cresceram aceleradamente desde a sua: institucionalização, mas as estatísticas do Banco do Brasil sobre o crédito rural só passaram a ser publicadas sistematicamente a partir de 1969. Neste ano, o total de financiamento atingiu a soma de 101.648.216 cruzeiros (em valores reais a preço de: janeiro de 1990) e, em 1979, já foram aplicados 515.548 .546 cruzeiros (em valores: reais a preço de janeiro de 1990) (SILVA, 1990). Toda essa expansão, conforme SAYAD (1984), deu-se a taxas de juros subsidiadas gerando uma demanda especulativa que se constituiu em importante fonte de distorção dessa política setorial.
} 
centração de recursos nas mãos dos grandes proprietários, além de duas outras formas de concentração: por regiào e por produto ${ }^{2}$

Os argumentos apresentados para explicar esse problema distributivo estão contrados, segundo Meyer et al. (1975) e Santos (1988), nos problemas da demanda (medo de assumir riscos e lidar com agôncias formais, falta de conhecimento de como usar o crédito e ausência de altemativas lucratuvas) e da oferta do crédito institucional (concentração do crédito, pouca participação dos bancos privados e falta de estimulo e interesse do sistema bancário para empréstimos aos pequenos produtores). No entanto, de acordo com Santos (1988), os problemas da distribuição social e espacial do crédito não deven ser excarados como uma distorção do programa de crédito rural, mas cono una conseqǘńcia da politica de modemizaçâo adotada. Isto porque: "As caracteristicas do crédito rural subsidiado atenderam às nocessidades dos formuladores da política de modemização da agncultura brasileira, já que os grandes produtores agricolas, aqueles que são mais facilmente atingidos pelo programa de crédito rural, são, também, os que têm condicôoes de mais rapidamente atenderem os incentivos de uso de insumos modemos na agncultura. O tipo de tecnologia disponivel direcionou o processo de modemização para os produtos exportáveis, como soja, café, açúcat e trigo (este, produto de importação do Brasil). Estes dois fatores, junto com melhores condiçoes de clima, melhor qualidade de solo e melhor nivel cultural dos produtores, direcionaram o processo de modemização para a regiāo Centro-Sul do Brasil" (SANTOS, 1988:402).

Muito embora a apropriação de grande parte do montante de recursos tenla sido feita, principalmente, pelos grandes proprietários, não se deve subestimar a influência desse mesmo crédito para uma

\footnotetext{
${ }^{2}$ Esses autores mostram, com clarcza, a concentração do crédito rural no Brasil, principalmente na década de 70 , em favor de alguns produtos, especialniente os dest inados à expottaçăo ou à industrializaçào, e em favor das regiões Sudeste e Sul. De acordo con a ASSESSOAR (1989), pelos dados fornecidos pelo Banco Central, em 1966 os pequenos produtores recebiam 34\% dos crédjtos concedidos; em 1976, passaram a receber apenas $11 \%$ do valor total do crédito. apesar de terern feito $74 \%$ do total dos contratos realizados e em 1987, apesar dos micro e pequenos produtores terem assinado $76 \%$ dos contratos do crédito rural, receberam apenas $20 \%$ do total dos tecursos.
} 
camada de pequenos proprietários. $O$ crédito rural contribuiu para 0 surgimento de uma nova classe de pequenos produtores, que se distanciou das concepções clássicas de campesinato. São os pequenos produtores tecnificados que se diferenciam com o aumento da sua importância social, tanto pelo sucesso econômico quanto pela capacidade para "modernizar-se" (PAULLLO, 1989).

Com o aprofundamento da crise brasileira a partir dos anos 80 , a política de crédito rural é redirecionada em função da condução da política macroeconômica do país, passando por fortes restrições de recursos e retirada gradual dos subsídios (SILVA, 1990). Com as dificuldades financeiras do Estado, a política de crédito rural começou, aos poucos, a se traduzir em redução dos percentuais dos financiamentos e em volume de crédito cada vez menor, mesmo sem subsídios, ou seja, os recursos tornaram-se cada vez menores, em termos reais, associados a um crescimento dos encargos financeiros. ${ }^{3}$

É importante destacar a forte intervenção estatal no crédito agrícola, seja na fixação das condições das operações creditícias (prazos e juros, entre outros), coordenação e controle dos programas de crédito, seja como agente financiador. A lei que institucionalizou o crédito rural no Brasil (Artigo $4^{\circ}$ ) dá competência ao Conselho Monetário Nacional para disciplinar o crédito com atribuições exclusivas para traçar suas normas operacionais. ${ }^{4}$ Desde a criação do SNCR, O Estado aparece como principal financiador dos programas de crédito agrícola, cujas fontes de recursos são o Tesouro Nacional e, no caso de muitos programas de investimento, organismos internacionais (Banco Mundial, Banco Interamericano de Desenvolvimento, entre outros). Mesmo com

${ }^{3}$ De acordo com os dados elaborados por SILVA (1990), o valor total de crédito agrícola caiu de Cr\$515.548.546 em 1979, para Cr\$176.017.662 em 1988 (valores reais a preço de janeiro de 1990).

${ }^{4}$ A Lei 4.595 , que criou o Conselho Monetário Nacional the confere, entre outras, as seguintes atribuições: "disciplinar o crédito em todas as suas modalidades e as operações creditícias em todas as suas formas, inclusive aceites, avais e prestações de quaisquer garantias por parte das instituiçóes financeiras". E em seu artigo 10, inc. $\mathrm{V}$, a lei confere ao Banco Central do Brasil competencia para "exercer o controle do crédito sob todas as suas formas". Citado por MORAES (1974:167-170). 
a criação e ampliação da exigibilidade bancária com base nos depósitos a vista e de outras fontes de recursos criados a partir de meados dos anos 80, como a Cademeta de Poupança Rural e o Fundo de Desenvoivimento Agropecuário, o Estado ainda permanece como principal agente financiador.

Nesse contexto, também aparecem os programas especiais de desenvolvmento conduzidos pelo Estado, que surgem como políticas compensatórias para os "exclúdos" do processo de modemização da agricultura. Quase sempre apresentando un discurso e una roupagem formalunente desconcentradora, esses programas, em sua maioria, adotam uma estratégia integrada, onde o crédito é um elemento do conjunto de serviços a ser proporcionado aos pequenos produtores. Entretanto, os resultados da implementação desses programas se afastam bastante das intenções manifestadas no conteúdo das suas propostas e os seus efcitos se apresentam nitidamente concentradores e exciudentes (Bursztyn, 1984; Chaloult, 1988; Martine \& Beskow, 1987, Sampaio et al., 1979).

Vale ressaltar que os estudos existentes sobre o crédito rural no Brasil centram-se, quase exclusivantente, no crédito agricola institucional, ou seja, enfatizam especialmente as operações realizadas no mercado fonnal ou institucional. ${ }^{\circ}$ Não obstante se reconheça que as tran-

${ }^{5}$ A exigibilidade de aplicação de parcela dos depósitos à vista em crédito rural foi estabelecida pelo govemo através das Resoluçōes $n^{\circ} 69$ e 260 do Banco Central do Brasil, visando ampliar a participaçào dos agentes financeiros privados do SNCR no financiamento da agricultura, ficando estipulado que os bancos devem aplicar $15 \%$ dos depósitos à vista em crédito rural, sob pena de recolhimento compulsótio em favor do Banco Central, caso aquele percestual não seja atingido. Atualmente. este percentual è de $25 \%$, conforme determina a circular BACEN n 1.696 de 25/04/90. Os sucessivos planos de ajuste económico adotados pelos Govemos a partir de entào, têm procurado reverter a tendência de queda no volume de crédito nưal buscando novas fontes de recursos no setor privado.

"Os termos formal e institucıonal são aqui utilizados como as atividades de créditopoupança em instituições influenciadas por regulamentos bancários: bancos privados e públicos, e cooperativas, legalmente reconhecidas, enquanto os termos informal e nâo institucional referem-se a outtras atividades de crédito-poupança entre amigos, parentes, comerciantes, indústrias, associaçôes de produtores, etc. 
sações informais de crédito perfazem uma proporção considerável do mercado de crédito rural, as informações sobre este mercado informal ou não institucional são pouco mencionadas, até porque elas não são disponíveis. Os poucos estudos que tratam desse assunto sugerem que as fontes não-institucionais de crédito são mais importantes para os pequenos agricultores do que para os médios e grandes, especialmente aqueles sem terra (os parceiros, por exemplo), que se utilizam dos financiamentos fornecidos pelos parentes, amigos, proprietários e comerciantes para atendimento das suas necessidades, inclusive de consumo.

Conforme adverte Meyer et al. (1975), são necessárias, entretanto, mais informações sobre a natureza e extensão do mercado informal de crédito rural, uma vez que há indícios de que a demanda por esse tipo de crédito varia em função da oferta e da disponibilidade do crédito formal. Nesse sentido, observam Silva et al. (1990), na conjuntura de restrição de recursos que marca o final da década de 80 e diante da falta de perspectiva de recuperação a curto e médio prazos do crédito agricola institucional, o setor rural tem buscado novas alternativas para financiar sua produção, onde se destacam: formas privadas coparticipativas de financiamento da indústria de insumo, da intermediação comercial e do processamento industrial; o financiamento de custeio da safra através do comprometimento de parte da produção futura realizada por algumas cooperativas, e o financiamento de máquinas e equipamentos através de consórcios, entre outras.

Como pode ser observado, estas alternativas combinam com a proposta de liberalização da economia apregoada pelo governo desde o início da década de 90 , em cuja concepção está implícita a modemização da agricultura sem a dependência da proteção do Estado. A modernização passa a ser entendida como a maior capacidade dos produ-

\footnotetext{
${ }^{7}$ O estudo realizado por BISERRA (1977) no Sertão do Ceará indica que o crédito informal (de parentes, amigos e dos proprietários fundiários) é comum a todos os grupos de produtores estudados, sendo bastante representativo no volume total de créditos recebidos pelos proprietários e parceiros que participam, respectivamente, com $78 \%$ e $89 \%$ do total.
} 
tores, em cada propriedade (ou empresa), de autosustentar-se, incrementar a produção e as rendas em condições de riscos de mercado e, também, pela maior necessidade de competitividade Esta concepcão não garante a possibilidade da incorporação dos pequenos produtores nesse processo sem um efeito compensador sobre suas rendas.

Estas alternativas certamente não se aplicam à pequena produção, exceto, talvez, àquele segmento de pequenos produtores cujas unidades de produção apresentam-se altamente tecnificadas e mercantis, mantêm intensas relações com o mercado de insumos e agroindústrias e se distanciam das formas de produçāo da imensa maioria dos pequenos produtores camponeses. Para estes, especialmente aqueles localizados nas áreas mais marginalizadas do Nordeste brasileiro, cujas atividades produtivas são desenvolvidas em condições adversas de clima e de mercado, tais altemativas se apresentam inexpressivas e inacessiveis, devido ao seu caráter de integração parcial a mercados incompletos, nos termos propostos por Abramovay (1990), ou seja, por sua ainda frágil relação com o conjunto das atividades industriais, comerciais e financeiras relacionadas à agricultura.

Esses pequenos produtores camponeses, em sua organização econômica, quase sempre encontram, na figura do pequeno comerciante, nos proprietários fundiários, nos amigos e familiares, a fonte de financiamento para o atendimento de suas necessidades de consumo produtivo imediato e familiar. Conforme Biserra (1977), dada a discriminação que sofrem em relação ao crédito institucional, esses produtores são forçados a recorrer às formas de empréstimos não-institucionais para equilibrar suas limitações de "capital".

\section{CRÉDITO AGRICOLA COOPERATIVO NO BRASIL}

As cooperativas agricolas poderiam, potencialmente, imprimir mais eficácia aos resultados dos programas de crédito, não somente pela ampliação do número de pequenos produtores beneficiados com financiamentos, mas, também, pela facilidade de adaptação desses programas às condições especificas de cada local, por melhores condicões de analisar as demandas dos agricultores e escolher os investimen- 
tos mais adequados a uma dada realidade. Entretanto, conforme destaca Pinto, (1981), apesar das poucas informações existentes sobre os financiamentos concedidos às cooperativas e a respeito da distribuição do crédito rural aos cooperados, deve-se ressaltar que a atuação delas restringiu-se ao simples papel de repassadoras dos empréstimos aos cooperados, segundo normas estabelecidas pelo SNCR, reproduzindo, portanto, os mesmos problemas do conjunto do sistema, inclusive de distribuição.

O regime jurídico das sociedades cooperativas, definido pela Política Nacional de Cooperativismo, limita a autonomia administrativa e financeira dessas sociedades, especialmente as cooperativas de crédito agrícola mistas e de habitação, cujas normas são baixadas pelo Consetho Monetário Nacional (MORAES, 1974).

Portanto, no Brasil, não foi desenvolvido um sistema de crédito rural cooperativo especializado em funções econômicas de poupança $e$ de crédito, e com estatuto jurídico parecido com uma instituição financeira. $O$ crédito cooperativo restringiu-se, principalmente, àquele repassado às cooperativas legalmente instituídas (segundo a Política Nacional de Cooperativismo), através do SNCR, de acordo com a legislação em vigor. Apesar de algumas iniciativas isoladas tomadas pelos próprios produtores, através de suas associações, no sentido de implementação de um sistema de crédito rural cooperativo, existe, ainda, uma série de restrições legais que impedem as cooperativas de funcionarem como as demais instituições financeiras. ${ }^{8}$ Não obstante esses obstáculos, há um florescente cooperativismo de crédito no país, especialmente no Rio Grande do Sul e São Paulo (RODRIGUES, 1987).

\section{CRÉDITO RURAL E DESENVOLVIMENTO}

O crédito agrícola no Brasil deve ser examinado em função da política de modernização da agricultura adotada no país, onde ele apa-

\footnotetext{
${ }^{8}$ Os principais obstáculos ao desenvolvimento do cooperativismo de crédito, na opinião de RODRIGUES (1987), são as normas do Banco Central do Brasil, que dificultam a participação das cooperativas de crédito na câmara de compensação de cheques e impedem uma justa remuneração dos depósitos a prazos.
} 
rece como principal instrumento de politica utilizado. cujas consequências sobre a redistribuição espacial e social dos beneficios c seus efeitos concentradores e excludentes já foram ressaltadas.

Com relação à agricuítura nordestina, ressalta Souza et al (1985), o crédito agrícola deve, também, ser examinado em função do papel a ele reservado pelo governo. Por isso, é necessário confrontar o seu desenvolvmento frente ao atual modelo. no qual a agrucultura nordestina. especialmente das regiōes semi-áridas de sequeiro, não apresenta vantagens comparativas em relação a outras regiỏes do pais. Num outro modelo que considere o desenvolvmento da economia brasileira de forma mais coerente e equilibrada, observa Souza (1985), o desenvolvimento da agricultura nordestina dar-se-ia mediante uma melhor utilização dos recursos naturais e socio-econômicos existentes, apoiado em techologias adaptadas à região. além do apoio financeiro adequado aos pequenos agrıcultores.

Mas não é o simples redirecionamento da politıca de crédito agnicola que irá corrigir as "distorções" do sistema oficial de crédito, de forma a bencficiar as regiões e as categonas de produtores mais necessitados Confonne observa Santos (1988), o problema é bem mais amplo e encontra-se ell nivel de formulação da política de modenuzacăo da agricultura brasileira, cujos objetivos precisan ser reformulados de forma a não refletir apenas as práticas de produção, mas un nivel de melhor estar social.?

Unıa politica de crédito agricola, como conponente do desenvolvimento rural para essas áreas margnnalizadas do Nordeste. deve incluir o financiamento das condiçōes técnicas e sociais de produção, on seja, deve conter créditos a longo prazo para o desenvolvimento agropecuário visando o financiamento de unia infraestrutura factivel, capaz de melhorar as condiçōes de produção dos pequenos agncultores (máquunas, animais, culturas permanentes, forrageiras, entre outras) e

${ }^{9}$ Para o autor. "Este conceito de mellıor estar social está intimamente ligado à atividade cconômıca que tem, por fim, a satisfação das necessidades humanas, na forma de alimentação, vestuários. habitação, saúde, cducação. recteação" (SANTOS, 1988:403). 
financiamento das operações agricolas. Tudo isso deve ser acompanhado de crédito para o desenvolvimento social, visando a melhoria da qualidade de vida das familias desses agricultores.

Num contexto geral de dificuldades econômicas do Estado, a situação atual no dominio do crédito rural pode ser caracterizada pela crise da grande estrutura oficial de financiamento da agricultura. A conjugação da crise e desequilibrio econônico, resultantes do esgotamento do próprio modelo de desenvolvimento, fez ruir o sistema de financiamento oficial, em decorrência da falência financeira da União, que se tomou incapaz de voltar a prover os recursos para o crédito rural

No final da década de 80, observa-se uma série de mudanças econômicas, sociais e políticas no pais. Como assinala Flores (1991), muitas delas vieram definir os parâmetros da evolução econômica futıra a partir do reconhecimento da exaustâo do modelo estatizante e centralizador de desenvolvimento. Com a constituinte de 1988, inaugura-se um periodo de redefinição do papel do Estado, sinalizando com medidas que buscam limitar a açäo governamental, fortalecer a iniciativa privada e atribuir maiores responsabilidades acs estados e municípios, quanto à promoção de seu próprio desenvolvimento (FLORES, 1991)

Nesse sentido, em relação ao crédito rural, já existem vários mecanismos altemativos de financiamento para agricultura partindo da iniciativa privada, mas, como foi visto, esses mecanismos também se colocam fora do alcance dos pequenos produtores camponeses

Embora se possa encontrar vínculos estreitos entre a crise do sistema de crédito rural oficial e as vias altemativas de financiamento da agricultura, não se pode tirar conclusões prematuras de que esses novos mecanismos substituem ou dispensam a participação oficial O Estado, certamente, continuará sendo o principal agente de promoção do desenvol vimento rural, inclusive para dar respostas às crescentes demandas sociais da população. E nesse sentido, ainda deverá ter, nos programas de financiamento oficiais, um dos instrumentos de política de desenvolvimento.

Aqui merecem destaque os Fundos Constitucionais de Financiamento das regiôes Norte, Centro-Oeste e Nordeste. Criados com o ob- 
jetivo de contribuir para o desenvolvimento econônico e social dessas regiōes, os fundos prevêem a execução de programas de financiamentos nos setores produtivos, en consonância com os planos regionais de desenvolvimento, cabendo a sua administracão ao Conselho Deliberativo das Superintendências de Desenvolvimento Regionais e a uma instituição financeira foderal de caráter regional. A esta última, entre outras atribuições, cabe gerir os recursos, definir nomas, procedimentos e condições operacionais, definir as faixas de encargos, fixar juros e definir os créditos (BNB, 1991).

Especificamente para o Fundo Constitucional de Financiamento do Nordeste - FNE, com recursos administrados pelo Banco do Nordeste do Brasil - BNB, pode-se reconhecer uma evolução na montagem dos programas oficiais de crédito, dado que apresenta um conteúdo técnico mais coerente com a problenática da região. E não obstante possa representar uma fonte de financiamento importante para o fortalecımento da estrutura produtiva da região semi-árida, a estratégia adotada para conferir "o tratamento preferencial às atividades produtivas de pequenos e mini-produtores", ${ }^{10}$ como determinam as diretrizes do Fundo, deixa dúvidas quanto à sua consecução.

Tal questionamento deve-se, sobretudo, ao que è considerado como pequetio produtor rural. O BNB segue o criténo adotado pelo Banco Central do Brasil, que considera o pequeno como o agricultor ou a empresa que obtém uma renda bruta anual esperada de até 2.400 Major Valor de Referência (MVR), podendo alcançar 6.000 MVR caso explore atividades mais intensivas, como sujnocultura. Tal critério tem o inconveniente de poder enquadrar grandes proprietários com poucas áreas exploradas ou proprietários de diversas áreas, pelo enquadramento individual por propriedades, na condição de pequeno produtor, podendo favorecer com subsidios ou subvenções quem precisa ou não. Trata-se, portanto, de um criténo que não é capaz de definir com precisão a categoria de pequenos produtores e se ressente de outros parâme-

${ }^{10}$ A Lei no 7827 , de 27.09.89, que disciplina a aplicacăo dos recursos constitucjonais, em seu art. $3^{0}$, estabelece "tratamento prefercncial às atridades produtinas de pequenos $\mathfrak{e}$ mini-produtores miras... bem como ans projetas de imigafão" (BNB. 1991:8) 
tros de classificação adaptados às condições particulares dos meios natural e humano.

Haveria a necessidade de serem postos em prática mecanismos apropriados, que assegurassem a participaçào dos pequenos produtores na elaboração das politicas de crédito agricola e capazes de influir nas decisões das instituiçôes bancánas. As organizações de produtores. através do estabelecimento de comitês de âmbito local, poderiam ser um passo nessa via (CARDOSO, 1985).

E preciso verificar as possibilidades de desenvolvimento de sistemas financeiros rurais (sistema de crédito cooperativo, por cxemplo). que sejam capazes efetivamente dc tomar-se um meio de dcmocratizar o acesso ao crédito agrícola e tomá-lo um instrumento de intervenção dos pequetios agricultores, em favor das suas próprias mniciativas.

A partıcipação das organizações camponesas locaıs na organızação, planejamento, operacionalização e controle dos programas de desenvoivimento volkados para a agricultura, poderia evitar desvios de recursos e de informaçôes e a burocratização dos serviços, além de propiciar a adaptação desses programas às condições específicas de cada local.

\section{CRÉDITO RURAL ALTERNATIVO}

Os pequenos produtores, como assmalado. sempre sofreram discrmmaçào em relação à estrutura oficial de financianıento. seja por falta de acesso a ela, seja por inadaptaçào das formas e modalidades de financiamentos às condições particulares dos recursos naturais e bumanos, não correspondendo, portanto. as suas reais necessidades. Em decorrência disto, já se esboçaram vanas experiências isoladas de financiamento rural a partir das inclativas tomadas, algumas delas, pelos próprios produtores, através de suas associações ou contando com o apoio de entıdades e institu çôcs voluntárıas de desenvolvinento em niveis local, regıona!, nacional e uternacional. São os conhecidos credıtos rurais altemativos, aqui entendidos e considerados como as diversas formas de sistemas de finauclamento rurais informais, conduzıdos por institulções ou organizações dos produtores aos niveis locais São eles 
os fundos rotativos, o crédito cooperativo de associações de poupança e crédito não oficrass, os fundos de desenvolvimento e os bancos de cereais, entre outros.

São sistemas financeiros desenvolvidos à margem das políticas e do mercado financeiro oficiais que assumen a fonna de crédito cooperativo na sua concepção mais simples e surgem como alternativas de financiamento que procuram democratizar o acesso dos pequenos produtores camponeses ao crédito rural, fazendo deste um instrumento dos agricultores, em favor de suas própnas uniciativas.

Esses sistemas de financiamento do setor nural diferem fundamentalmente do sistema de crédito agricola oficial Enquanto este, conforme Gentil \& Foumier (1991), tem se caracterizado pela sua vinculação à promoção de determinadas culturas e pelo seu atrelamento a "pacotes tecnológicos", aqueles, contrariamente, respondem às necessidades reais expnumidas pelos agnicultores e caracterizam-se pela flexibilidade das formas e modalidades de financiamento

Porquanto, para que se tome acessivel a um maior nimero de beneficiártos e não venha agravar aında mais o processo de diferenciação econômica e social, o desenvolvimento dos sistemas de financiamentos rurais informais geralmente necessita de muitos ajustes e adaptaçōes, para que possa cumprir seus objetivos. Entre outras adequações ımportantes que caractenzam esses sistemas de financiamentos, podem-se citar: acesso do produtor às informações sobre o funcionamento do sistema, aos recursos dos fundos e ao apoio técnico e econômico de um agente local da comunidade, que inspire confiança ao produtor e que conheça o ambiente local, conforme sugerem Ellsasser \& Diop (1990); formas de pressão social para o reembolso - a pressão não pode se basear em penalıdades, judiciàrias ou fiscais, porque são completamente ineficientes, nem em exigências de garantias, porque elas quase sempre não existem; financiamento que dá toda a liberdade à expressão das oportunidades cconômicas identificadas pelos produtores, não fícando restrito, portanto, às atividades meramente voltadas para a agropecuária. Sabendo que o produtor é quem melhor conhece a realidade local, ninguém melhor que ele para definis as atividades a serem implementadas. Por outro lado, não é a definição "a priori" das atividades a serem 
financiadas que ıá garantir o reembolso pelos produtores. Isso, entretanto, não prescinde do apoio técnıco e econômico, apropração do sistema de financiamento e participação dos produtores, apoiando-se em formas institucionais de organização apropradas e descentralizadas, conforme sugere Cardoso (1985). Essa é uma condição indispensável para garantir a perenidade do instrumento de financiamento e proporcionar confrança dos produtores no sistema, que, por sua vez, só é possivel, à medida que eles tenham a garantia que poderão ser beneficiários do sistema sempre que necessáno.

Sabe-se que o financiamento de atıvdades diversificadas assume uma importância prmordial para os pequenos agncultores, especialmente aqueles localizados nas áreas sem-áridas, onde o equilibrio econômico, social e natural é instável. Esses financıameıtos podem permitir aos grupos sociais, cujo principal recurso disponivel é a mão-de obra, a possibilidade de valonzá-la, com a implementação dessas atividades diversificadas (transformação de produtos, pequeno comércio, artesanato, etc ).

Mas conforme Caron \& Silva (1992), uma questão se apresenta como primordial quando se trata do financiamento de atividades rurais diversıficadas: quais são as possibilidades e opoıtunıdades de produção que podem exprimir um espaço econômico favorável especifico a cada região, que preservem os recursos naturais e garantam a reprodução do grupo social?

No entanto, quando os produtores dispõem de um minimo de mejos (financeiros e de produção), eles apresentam uma grande capacidade criatıva e. conforme demonstra Nowak (1988), o financiamento permite, então, às populações mais carentes, crarem suas própras atividades produtivas e romperem con a situação de dependência e penúria em que nvem. Moreno (1991) mostra que existe uma margem de progresso potencial, quando se dispõe a escutar a população rural, conhecer os sıstemas agrários e a evolução e potencıalidades dos sistenas de produção rural aos niveis local e regional. Este conhecimento é essencial ao desenvolvimento dos sistemas de financiamentos rurais. De acordo com Moreno (1991), a uma dada situação agrária (organização agrária, prática de produção nural, trocas, acumulação, relações sociais, etc.), 
corresponde un determinado sistema de financiamento (fluxos financelros, de insumos e de produto).

Os sistemas de funanciamentos rurais informais sempre aparecem corroborando com as dinâmicas de desenvolvimento local e contribuindo para a viabilização de um modelo de agricultura que valoriza os recursos humanos e naturais. Entretanto, a natureza, as modalidades e as formas que assume esse financiamento são as mais diversas (fundos rotativos, crédito cooperativo de associaçòes de poupança e créditos não oficiais e bancos de cereais, entre outras) (Gentil \& Foumier, 1991)

\section{CONCLUSŌES}

Os pequenos produtores da região semi-árida do Nordeste ficaram à margen dos beneficios dos programas oficiais de crédito e desenvolvimento rural conduzidos pelo Estado. visando a modernização da agncultura. A forte intervenção estatal na fixação das condiçôes de operaçōes e controle desses programas prejudicou a emergência de um sistema cooperativo de crédito rural e contribuiu, ainda mais, para o alyamento desse segmento de produtores. As novas formas altemativas para financiar a produção agropecuária, que surgem após as politicas de restrições de recursos para crédito nural oficial, a partir dos aros 80 , também não se aplicam à pequena produção camponesa. principalmente aquela localizada nas áreas mais marginalizadas do Nor-deste, submctudas às adversidades de clima e de mercado

Diante das diversidades do quadro natural e da situação socioeconòmica da região. surge a necessidade de implementação de mecausmos de financiamentos simples, adaptados e adequados às particulandades da região e às especificidades dos pequerıos produtores, contempiando a participação destes na sua orientaçào, gestão e operacionalização. Nesse sentido, os sistemas informais de crédito cooperativo aparecem como uma altemativa de financiamento agricola, que não depende apenas das politicas oficials ou do mercado financeiro, mas que pode assumir um caráter complementar nas políticas de desenvolvimento rural. 
Finalmente, resta um questionamento: $\mathrm{cm}$ que medida as experiências existentes de sistemas cooperativos informais de financiamento rural, devdamente analisados, podem contribuir para uma reflexão sobre o crédito rural institucional? Diante desse desafio, a valorização dos resultados dessas experiências requer estudos mais específicos

\section{REFERÉNCIAS BIBLIOGRÁFICAS}

ABRAMOVAY, R. De Camponeses a igraculiores: Pardigmas do Copusalismo flgrário em Quesião. Campinas: Universidade Estadual de Campinas, Instituto de Filosafia e Ciências Humanas, 1990. 354p. Tese de Doutorado

ASSESSORIA DE ESTUDOS, ORIENTAÇÃO E ASSISTÊNCIA RURAL (ASSESOAR) (Rio de Janeiro, RJ). Fundo Rotativo: Uma Proposta de Crédito illemativo a ser Consinuide e Experimenteda. Francisco Beltrão, PR, 1989. 16́p

BANCO DO NORDESTE DO BRASIL (Fortaleza, CE). FNE Findo Constumcional de Financiamento do Nordeste. Fortaleza, 1991. 37p.

BISERRA, J.V Unilzafẫo do Crédito Rural pelos Agricultores de Baixa Rendo do Sertão Central do Ceartí. Fortaleza. UFCE, 1977. 34p.

BURSZTYN, M. O Poder dus Donus: Planejamento e Clientelismo no Nordeste Petrópolis: Vozes, 1984. I78p.

CARDOSO, J.L. "Crédito Rural um Elemento de Diferenciação dos Pequenos Produtores". Perspectivas. São Paulo, V.8, p.85-93, 1985.

CARDOSO, J.L. "Política de Crédito Rural no Brasil: Uma Análise dos Dados Estatisticos de 1983 a $1985^{\circ}$ in XII Encontro Nacional do Projeto de Intercâmbio de Pesquisas Socjais em Agricultura (PIPSA), Rio de Janeiro, [988. V.2, p. 773-80]

CARON, P. \& SILVA, P.C.G. da. Pequenes Produção e Desemelvimento Sustentival: A Necessidade de um Sistema de Crédiso Adaptado. Fortaleza, CE, ICID, 1992.8p.

CHALOULT. Y. Govemo de Transifäo com l'elhas Práticas: O que Sobra paro o Trobalhadre do Campo. [s.n.t.] Trabalho apresentado no XIII Encontro Nacional do Projeto de Intercâmbio de Pesquisas Sociais em Agricultura (PIPSA). Rio de Janeiro, jur. 1988. (mimeo). 
DELGADO. G. da C. Capiral limancerro e Agriculinra no Brasil: 1965 1985 São Paulo, UNIC AMP/CONE, 1985. 240p.

ELLSASSER, $K$ \& DIOP. M. La Bangue Frpeimmentale de Banh: (hite Demarche de Recherche-Développemens sw. le Crédit on Milien Sahélien. Montpelljer, CIRAD/DSA, $199037 \mathrm{p}$.

FLORES, M.X. O Desenulvimento Rural c o Setor Público Agricola: A Questão Techológics e umo fgenda para o lintendimeno. Brasitia: EMBRAPA-SEA. 1991. 23p. (EMBRAPA-SEA Documentos, 7).

GENTIL, D., FOURNIER, Y. Fmancement Local Paris, I.R.A.M., 1991. $33 \mathrm{p}$.

HOFFMANN, R. \& KAGEYAMA. A.A. "Crédito Rural no Brasil: Concentração Regional e por Cultura". Revista de Economia e Sociologia Rural. Brasilia, SOBER, V.25, n.1.p.31-50, 1987

MARTINE, G. \& BESKOW, P.R. "O Modelo, os Instrumentos e as Transformações na Estrutura de Produção Aggricola" in MARTTNE, G. \& GARCLA, R.C. (org.) Os Impaclos Sociass do Modemização dgricola. São Paulo, Caetés, 1987. pp.19-39.

MEYER, R.L., ADAMS, D.W., RASK, N. \& ARAUJO, P.F.C. de. "Mercados de Crédito Rural e os pequenos Agricultores do Brasil" in: ARAUJO, P.F.C. de \& SCHUH. G.E Desenolvimenso da igricultura: Inólise de Politica feconomica. São Paulo, Pioneira, 1975. pp. 151-204.

MORAES, J.A. "O Crédito como Fator de Desenvolvimento das Cooperatjvas Brasileiras" in Fundação Friedrih Naumann (São Paulo, SP) . A Problemálica Cooperativa no Desenrolumento Econömico. São Paulo, Fundação Frederic Neumann, 1974. pp.167-183.

MORENO, A. Devcloppement des Systimes Financiers Ruraur. Montpellier, CIRADDSA, $19916 p$.

MUNHOZ, D.G. Economia agricola: Agricultura - uma Defesa dos Subsidios. Petrópolis, Vozes, 1982, 107p.

NOWAK, M "Une Banque pous les Pauves: La Graalınen Banque Carrier". Institut d'Etudes Sociales de Lyon, $\mathrm{n}^{0}$ 1, pp. 23-29. 1988.

PaUluLO. M.IS. "Crédito Agricola e Pequena Produção" in Planeiamento e Políticas Públicas. Brasilia, IPEA. n² 2, pp.93-1]2, 1989. 
PINTO, L.C.G Notas sobre a Politica de Crédito Rural. Campinas: UNMCAMP, 1981. I43p. (Mimeo)

RODRIGUES, R. Cooperativismo de Crédito Rural in: Congresso Brasileiro de Economia e Sociologia Rura!, 25, 1987, São Luís, MA. Anais.. Brasilia, SOBER, 1987, pp.113-116.

SAMPAIO, Y., GOMES, G.M \& IRMÄO, J.F. Politica Agricola no Nordestc. Imenfôes e Resultudos. Brasilia, BNAGRI, 1979.360p.

SANTOS, R.F. dos. "O Crédito Rural na Modernização da Agricultura Brasileira". Revista de Economia e Sociologia Rural, Brasilia, SOBER. V.26, $a^{2} 4,1988$, pp.393-404.

SAYAD, J. Crédito nural no Brasil: Avaliaģão das Criticas e das Propostas de Reforma. São Paulo, Pioneira, Fundação Instituto de Pesquisas Económicas, 1984. 125p.

SILVA, J.G. da. A Modemização Dolorosa: Estruhura Agräria, Fronteira Agricolo e Trabalhador Rural no Brasil. Rio de Janeiro, Zahas, 1982. $192 p$.

SLVA, V. da. "Crédito nural: Nova Década, Novos Rumos" in Informações Econômicas. São Paulo, Instituto de Economia Agricola, Secretaria de Agricultura, V.20, $n^{0} 7,1990$, pp.21-27.

SLVA, V. da, GATTI, E.U. \& TOLEDO, Y.I.M. de. "Financiamento Agricola: Situação Atual, Crédito Oficial e Altemativas" in Informações Econômicas. Sảo Paulo, Instituto de Economia Agricola, Secretaria de Agricultura, V.20, $\pi^{2}$ 7, pp.37-4I, 1990.

SORJ, B. Estado e Classes Sociais na Agricultura Brasileira. Rio de Janeiro, Zahar, 1980. 152p.

SOUZA, R.A. de, VTVALLO PINARE, A.G., WILLLAMS FUENTES, C.O. \& FWSHT, R.P. Consideração sobre o Crédito Agricola: o Caso de Ouricuri-PE. Petrolina, PE, EMBRAPA-CPATSA, $1985.29 \mathrm{p}$. (EMBRAPA-CPATSA. Documentos, 34). 